\title{
First Report on Fusarium brachygibbosum Isolate FIR 16_ITS Isolated from Iraqi Wheat Plant
}

\author{
Hamdia Z. Ali ${ }^{* *}$, Mahdi S. Hameed ${ }^{2}$, Abdulrahman A. Abdulrahman', \\ Hutham M. Saood ${ }^{1}$ \\ 1 Agriculture Research Directorate, Integrated Pest Management Center, Ministry of Science and Technology, \\ Baghdad, Iraq \\ 2 Biotechnology Center, Agriculture Research Directorate, Ministry of Science and Technology, Baghdad, Iraq \\ * Corresponding author's e-mail: hamdiazali3@gmail.com
}

\begin{abstract}
In this study, the Fusarium Brachygibbosum fungus isolate FIR 16 ITS was isolated for the first time from the infected wheat plants in Iraq, during the winter of 2018, in the AL-Tewatha region - $20 \mathrm{~km}$ south east of Baghdad. In order to verify the identity of the species of the F. brachygibbosum isolate FIR 16 ITS with the growth symptoms on the wheat plants, the wheat seeds and tissue plants were obtained and used as a source for the re-isolation of the infection agent. F. brachygibbosum isolate FIR 16_ITS was hardly identified using visual approach. However, a molecular technique is important in verifying the species of F. brachygibbosum isolate FIR 16_ITS. The isolate obtained was used for the extraction of DNA and later used for the molecular identification and phylogenetic analyses based on rDNA-internal transcribed region (ITS) primer sets. The authors successfully obtained the amplified products of the ITS-rDNA region, and a sequence analysis indicated that the Fusarium sp. isolate FIR 16_ITS species screened in this study belonged to the F. brachygibbosum species. It was recorded in the NCBI under the following information NCBI; BioSample; Accession no.; SAMN11408139; ID: 11408139 and NCBI; BioProject; Accession no.; PRJNA532637; ID: 679434 (Locus Tag Prefix; E7750).
\end{abstract}

Keywords: phylogenetic analyses, rDNA, Iraq.

\section{INTRODUCTION}

F. brachygibbosum is a filamentous fungus, and considered one of the most important groups of Ascomycetous fungi, Class: Sordariomycetes, Subclass: Hypocreomycetidae, Order: Hypocreales, Family: Nectriaceae, Genus: Fusarium, Species: Fusarium brachygibbosum [Tan et al. 2011; Al-Sadi et al. 2012; Chitambar 2016; Shan et al. 2017; Cao et al. 2018]. This fungus is considered a soil-borne plant pathogen, and has a broad spectrum distribution worldwide and also is responsible for severe economic losses due to reducing yield [Punja et al. 2018]. F. brachygibbosum survives in the soil as asexual spores (microconidia and macroconidia) [Chitambar 2016].

F. brachygibbosum was identified based on its morphology by Padwick [1945], and later recognized as $F$. brachygibbosum by biochemical characteristics, including the sequencing of large subunit (26S) ribosomal DNA analyses [AlMahmooli et al. 2013; Mirhosseini et al. 2014; Rentería-Martínez et al. 2015; Chitambar 2016]. F. brachygibbosum pathogen exists in legumes [Tan et al. 2011], and has a high potential to infect and reduce the wheat growth and productivity. It produces the symptoms similar to the results obtained with Fusarium head blight disease on wheat in South Africa [Van Coller et al. 2013]. Moreover, Al-Sadi et al. [2012] and Gashgari et al. [2016] found the F. brachygibbosum isolates in date palm plants and medicinal plants. Moreover, in Iran, Mirhosseini et al. [2014] found F. brachygibbosum caused leaf spot on oleander. The life cycle of this fungus has not been reported specifically. Hence, it was correlated to 
other Fusarium species causing canker and wilt disease. F. brachygibbosum can also effect on the growth of cold-stored, bare-root nursery almond trees in California [Seidle 2016], maize [Shan et al. 2017], olive trees [Trabelsi et al. 2017]. Moreover, F. brachygibbosumi caused a decline of almond trees [Stack et al. 2017], sunflower [Xia et al. 2018] and sugar beet [Cao et al. 2018].

F. brachygibbosum has a high ability to infect the seeds of plants below the soil surface, pods, roots, leaves, stems and plant debris that leads to many symptoms such as vascular wilts, crown rot in field, dieback, and cankers on almond branches [Stack et al. 2017], lesion and wilting on leaves of whole watermelon plants [Boughalleb et al. 2005; Renteria-Martinez et al. 2015; 2019], leaf spots in oleander [Mirhosseini et al. 2014]; also, the spots symptoms were observed on cannabis plants (Cannabis sativa) in northern California, and this was later recognized as the pathogenic fungus [Punja et al. 2018].

Wheat (Triticum aestivum L.) is considered first crop in Iraq, but its productivity is lower than the global level of production in developed countries [Minati and Mohammed 2019]. This is due to insufficient scientific methods to cultivate and produce this crop and service it. The wheat production was decreased in 2018 by 2178 thousand tons; a decrease of $26.8 \%$ compared to the 2017 production amounted to approximately 2974 thousand tons (Central Statistical Organization 2018). In the developed countries, wheat is infected with Fusarium species and the destructive effects of this pathogen on cereal grains continue to date, which causes losses in most wheat-producing countries due to direct damage to spikes, which are often completely empty of grains, and produce fungus. In this study, the $F$. brachygibbosum isolate FIR 16_ITS was isolated and identified from the wheat plants. Recently, the authors have extensively worked to discover the role of $F$. brachygibbosum isolate FIR 16_ITS in the Iraqi wheat plants.

\section{MATERIALS AND METHODS}

\section{Isolation of the F. brachygibbosum isolate FIR 16_ITS}

The F. brachygibbosum isolate FIR 16_ITS samples were collected during the year 2018 from the infected wheat plants in the AL-Tewatha region $-20 \mathrm{Km}$ south-east of Baghdad. It caused severe damage to the wheat plants and reduced the plant production.

F. brachygibbosum isolate FIR 16_ITS was isolated from the local wheat variety tissue (cv. Iba) through surface sterilising the tissue with $1 \%$ sodium hypochlorite for $2 \mathrm{~min}$. The tissue was then washed in distilled water for several times before drying on a filter paper and culturing on potato dextrose agar (PDA) plates. A pure culture of the F. brachygibbosum isolate FIR 16_ITS was cultured on the PDA medium and incubated at $28^{\circ} \mathrm{C}$ to obtain fresh single spore. Individual spores were isolated and sub-cultured on the PDA plates to obtain $F$. brachygibbosum FIR 16_ITS. Moreover, one $(1 \mathrm{~g})$ of soil was obtained from the rhizosphere area of wheat plants variety $\mathrm{cv}$. Iba was dissolved in $50 \mathrm{~mL}$ of distilled water, homogenised and vortexed for $15 \mathrm{~min}$. Then, $1 \mathrm{~mL}$ of the suspended soil solution was added to $9 \mathrm{~mL}$ of sterilised distilled water in a tube $\left(10^{1}\right)$. The content of this tube was vortexed, then $1 \mathrm{~mL}$ was subsequently transferred to another $9 \mathrm{~mL}$ sterilized distilled water in a tube $\left(10^{2}\right)$, and this volume was serially diluted to $10^{6}$ [Hamdia 2014]. Exactly $10 \mu$ of dilution $10^{4}-10^{6}$ was transferred into the PDA plates via spread plating to obtain a fresh colony forming unit (CFU).

\section{Isolation of Genomic DNA from F. brachygibbosum isolate FIR 16_ITS}

For the extraction of the fungal genomic DNA, a single spore of $F$. brachygibbosum isolate FIR 16_ITS, was transfered to the flasks containing $100 \mathrm{~mL}$ potato dextrose broth (PDB) medium. These cultures were grown at $28^{\circ} \mathrm{C}$ incubator shaker with agitation of $150 \mathrm{rpm}$ for four days at $28^{\circ} \mathrm{C}$ and the mycelium was harvested aseptically via filter paper [Hamdia 2014]. Exactly one hundred (100) mg of mycelial tissue was ground for several minutes in $1 \mathrm{ml}$ of cetyltrimethylammonium bromide $(2 \times \mathrm{CTAB})$ buffer plus $2 \mu \mathrm{L}$ of $\beta$-mercaptoethanol and $1 \mu \mathrm{L}$ of RNase were added. This method was based on the Murray and Thompson [1980] protocol with a slight modification. These were mixed vigorously for $10 \mathrm{~s}$ and kept on ice for $5 \mathrm{~min}$, vortexed and incubated in water bath at $65^{\circ} \mathrm{C}$ for $1 \mathrm{~h}$. The contents were mixed by inverting each tube for $15 \mathrm{~min}$. They were kept at room temperature for $5 \mathrm{~min}$ and centrifuged at $13,000 \mathrm{rpm}$ for $10 \mathrm{~min}$ at $4{ }^{\circ} \mathrm{C}$. Five hundred (500) $\mu \mathrm{L}$ of supernatant was obtained 
poured into a freshly sterilized $2 \mathrm{~mL}$ tube. Then, $500 \mu \mathrm{L}$ of chloroform: isoamylalcohol (24:1) was added to the above-mentioned suspension, vortexed and centrifuged at 13,000 rpm for $10 \mathrm{~min}$. This process was repeated twice to avoid proteins and was mixed well. Exactly $500 \mu \mathrm{L}$ of supernatant was obtained and poured into a freshly sterilized $2 \mathrm{~mL}$ tube. Then, $820 \mu \mathrm{L}$ of cooled isopropanol was added, and incubated overnight at -20 ${ }^{\circ} \mathrm{C}$.

The sample replicates were centrifuged at $13000 \mathrm{rpm}$ for 15 minutes at room temperature, and the pellet was washed with $70 \%$ ethanol twice; pellet was dried completely for $1-2 \mathrm{~h}$ and dispensed with $\mathrm{ddH}_{2} \mathrm{O}$ to rehydrate the genomic DNA. The quality of DNA was estimated spectrophotometrically via the NanoDrop 1000 (Nanospec cube, Germany). The concentration of DNA was visualised by electrophoresis on $1 \%$ $(\mathrm{w} / \mathrm{v})$ agarose gel (Vivantis, USA) in $1 \mathrm{X}$ TAE buffer and stained with $4 \mu \mathrm{L}$ of ethidium bromide $\left(0.5 \mu \mathrm{g} \mathrm{mL}^{-1}\right)$ solution. The gel was electrophoresed at $80 \mathrm{~V}$ for $\sim 55 \mathrm{~min}$. The samples were mixed with $2 \mu \mathrm{L}$ of loading dye ( 6 X Ficoll dye) and loaded into the wells. The DNA bands in the gel were visualised under UV-Transilluminator (Cleaver Scientific, Ltd, UK) with camera Canon. The DNA size was determined by comparing with the molecular weight marker ladder $(1 \mathrm{~Kb}$ DNA ladder, Promega, U.S.A, $0.1 \mu \mathrm{g} \mu \mathrm{L}^{-1}$ ) and then stored at $-20^{\circ} \mathrm{C}$.

\section{Verified identities of $F$. brachygibbosum isolate FIR 16_ITS via ITS-rDNA Amplification of rDNA Internal Transcribed Spacers (ITS)}

The specific primers (ITS-4 and ITS-5) were used to amplify the ribosomal DNA (rDNA) of F. brachygibbosum isolateFIR 16_ITS fungus. The forward and reverse primer pair used in this study are ITS4-F-5'TCCTCCGCTTATTGATATGC3' (20 mers) and ITS5-R5'GGAAGTAAAAGTCGTAACAAGG3' (22 mers) [White et al. 1990]. The primers were synthesized at Bioneer Company and supplied as lyophilised product of desalted oligos. The reactions were performed in $25 \mu \mathrm{L}$ tubes with Taq Promega (USA), and the thermal cycling conditions used are as follows: $94{ }^{\circ} \mathrm{C}$ initial denaturation cycle for $4 \mathrm{~min}$ followed by 35 cycles of $94{ }^{\circ} \mathrm{C}$ for $1 \mathrm{~min}, 55^{\circ} \mathrm{C}$ for $1 \mathrm{~min}$ and $72{ }^{\circ} \mathrm{C}$ for $2 \mathrm{~min}$, and then a final extension at $72{ }^{\circ} \mathrm{C}$ for 10 min. The PCR products were checked on $1.0 \%$ agarose gel. The PCR products were purified using a PCR purification kit (Bioneer Company, Korea). The purified PCR products were sent to Bioneer Company Corporation for sequencing. The sequence was converted into a consensus sequence by using BioEdit Program ClustalW. The resulting consensus sequence for the F. brachygibbosum isolate FIR 16_ITS was blasted against the whole nucleotide sequences in GenBank via National Center for Biotechnology Information (NCBI).

\section{Phylogenetic analysis of $F$. brachygibbosum isolate FIR 16_ITS}

The DNA sequence was aligned using the ClustalW (http://www.ebi.ac.uk/Tools/msa/clustalw2/) option available in BioEdit Sequence Alignment Editor Version 7 followed by manual adjustment [Hall 1999]. The bioinformatics tool and multiple sequence alignment were employed using ClustalW. The sequences were analysed in Mega version 6.2 [Tamura et al. 2013] by using the partition homogeneity test. The molecular phylogenetic used a maximum parsimony (MP) [Nei and Kumar 2000]. Under the MP criterion, the topology requiring the smallest number of nucleotide changes to fit the observed sequence data is chosen to represent the true tree. MP is thought to be nonparametric, that is, it does not require specification of a model of evolutionary change.

\section{RESULTS}

\section{PCR amplification of ITS-rDNA sequences of F. brachygibbosum isolate FIR 16_ITS}

In order to verify the identity of the organism with the disease symptoms on wheat plants, the wheat seeds from infected plants were obtained and used as a source for the re-isolation of the causal agent. The fungal isolates obtained were used for the extraction of DNA and later for the molecular verification with specific ITS primer sets. The authors successfully obtained the amplified products of the ITS-rDNA region of the F. brachygibbosum isolate FIR 16_ITS. The PCR products obtained with the specific ITS primers used are presented in Figure 1. The PCR product size was within the range of $600 \mathrm{bp}$. 


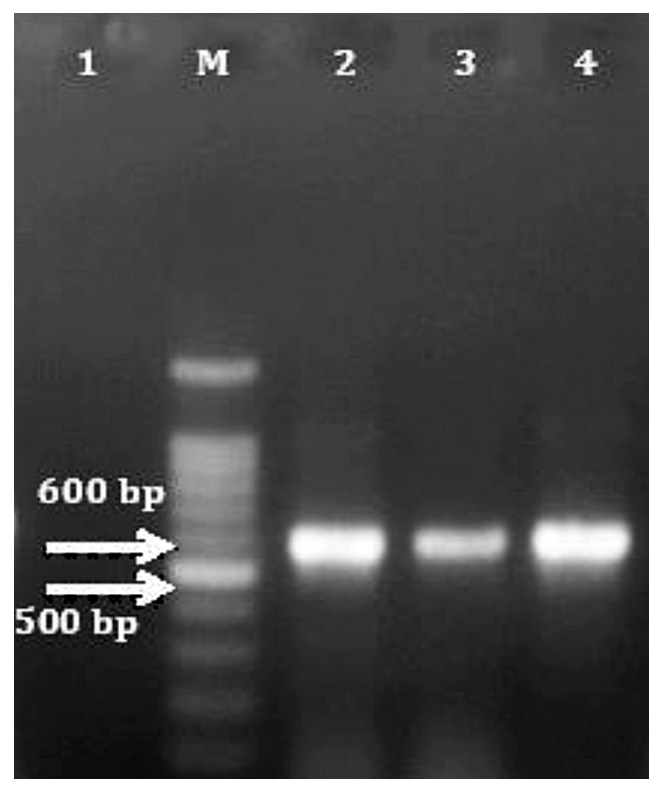

Fig. 1. Agarose gel electrophoretic profile of ITSPCR amplification of $F$. brachygibbosum isolate FIR 16_ITS.Lane M: 100 bp ladder (Promega, U.S.A); Lanes 1: control. Lane 2-4: PCR amplicon of $F$. brachygibbosum isolate FIR 16_ITS

\section{Phylogenetic relationship of F. brachygibbosum isolate FIR 16_ITS}

The evolutionary history was concluded using the MP method. Figure 2 provides the phylogenetic analysis of ITS sequences obtained for 41 isolates of F. brachygibbosumi from GenBank database of the NCBI. These sequences were downloaded and used in the MP analysis. The strict consensus tree was generated by summarising the most parsimonious tree that generated seven clades (bs $=100 \%)$. The location of the sequence of ITS-rDNA obtained from the F. brachygibbosum isolate FIR 16 ITS cultures re-isolated from our wheat tissue was nested within the second sub-clade of clade fourth. It was clustered together with the three following isolates: F. brachygibbosumi isolate DLP41S3a1 > MK757199.1 isolated from genomic DNA; F. brachygibbosumi isolate MH127Trs > MK817053.1 isolated from Grapevine Rootstock; F. brachygibbosumi strain MS-R1 > KF843733.1 isolated from soil from Mediterranean forest. The tree analysis of the ITS sequences and high homology (80\%) indicated a close relationship with one species of F. brachygibbosumi sequence isolated from genomic DNA and supported that the F. brachygibbosum isolate FIR 16_ITS caused disease on the wheat plants in this study as F. brachygibbosumi.

\section{CONCLUSION}

In this study, the authors isolated the F. brachygibbosum isolate FIR 16_ITS, and successfully obtained the amplified products of the ITS-rDNA region and sequence analysis. On the basis of the amplified ITS region of $F$. brachygibbosum isolate FIR 16_ITS, the results verified the identity of F. brachygibbosum isolate FIR 16_ITS used in this study. However, more work is required to develop a new strategy to control this pathogen with suitable formulation that helps promote the wheat growth and suppress the wheat pathogen.

\section{Acknowledgement}

The researchers would like to thank the Directorate of Agricultural Research, Ministry of Sciences and Technology for their help to complete this research.

\section{REFERENCES}

1. Al-Mahmooli I.H., Al-Bahri Y.S., Al-Sadi A.M. and Deadman M.L. 2013. First report of Euphorbia larica dieback caused by Fusarium brachygibbosum in Oman. Plant Disease, 97(5), 687. https://doi. org/10.1094/PDIS-09-12-0828-PDN.

2. Al-Sadi A.M., Al-Jabri A.H., Al-Mazroui S.S. and Al-Mahmooli I.H. 2012. Characterization and pathogenicity of fungi and oomycetes associated with root diseases of date palms in Oman. Crop Protection, 37(1), 1-6. https://doi. org/10.1016/j. cropro.2012.02.01.

3. Boughalleb N.,Armengol J. and Mahjoub M.E. 2005. Detection of races 1 and 2 of Fusarium solani f. sp. cucurbitae and their distribution in watermelon fields in Tunisia. Journal of Phytopathology, 153, 162-168. https://doi.org/10.1111/j.1439- 0434.2005.00947.

4. Cao S., Yang N., Zhao C., Liu J., Han C. and Wu X. 2018. Diversity of Fusarium species associated with root rot of sugar beet in China. Journal of General Plant Pathology 1-9. https://doi.org/10.1007/ s10327-018-0792-5.

5. Central Statistical Organization. Iraq. 2018.

6. Chitambar J.J. 2016. California Department of Food and Agriculture. California pest rating for $\mathrm{Fu}$ sarium brachygibbosum Padwick 1945. Accessed 2018 Apr 3. cdfa.ca.gov/Section3162/?p=2586.

7. Gashgari R., Gherbawy Y., Ameen F. and Alsharari S. 2016. Molecular characterization and analysis of antimicrobial activity of endophytic fungi from medicinal plants in Saudi Arabia. Jundishapur 


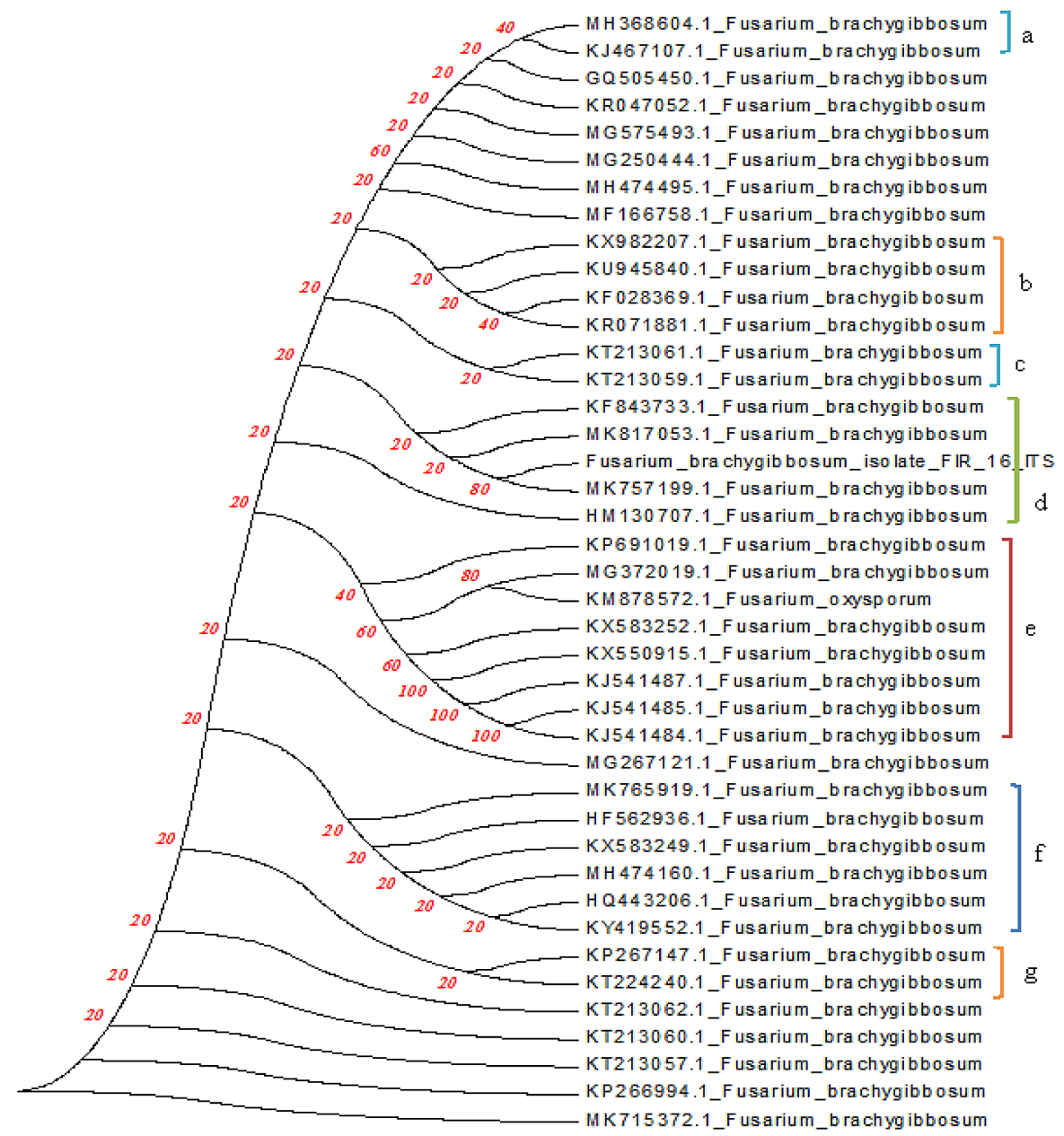

Fig. 2. Maximum Parsimony Analysis of taxa. The evolutionary history was inferred using the Maximum Parsimony method. The consensus tree inferred from 5 most parsimonious trees is shown. The branches corresponding to the partitions reproduced in less than $50 \%$ trees are collapsed. The consistency index is $0.891156(0.761194)$, the retention index is $0.831579(0.831579)$, and the composite index is $0.741067(0.632993)$ for all sites and parsimony-informative sites (in parentheses). The percentage of parsimonious trees in which the associated taxa clustered together is shown next to the branches. The MP tree was obtained using the Tree-Bisection-Regrafting (TBR) algorithm (pg. 126 in ref. [Nei and Kumar 2000] with search level 0 in which the initial trees were obtained by the random addition of sequences (100 replicates). The tree is drawn to scale; with branch lengths calculated using the average pathway method, see pg. 132 in ref. [Nei and Kumar 2000] and are in the units of the number of changes over the whole sequence. The analysis involved 41 nucleotide sequences. The codon positions included were $1 \mathrm{st}+2 \mathrm{nd}+3 \mathrm{rd}+$ Noncoding. There were a total of 1420 positions in the final dataset. The evolutionary analyses were conducted in MEGA6 [Tamura et al. 2013].

Journal of Microbiology 9(1), e26157. https://doi. org/10.5812/jjm.26157.

8. Hamdia Z.A. 2014. Efficiency of Trichoderma isolates and Bacillus subtilis UKM1 as biocontrol agents against Magnaporthe grisea, Rhizoctonia solani and Fusarium solani in wheat. PhD Thesis. Faculty of Science and Technology. Universiti Kebangsaan Malaysia. Malaysia.

9. Hall T.A. 1999. BioEdit: a user-friendly biological sequence alignment editor and analysis program for windows 95/98/NT. Nucleic Acids Symposium Series, 41, 95-98.
10. Minati M.H. and Mohammed-Ameen M.K. 2019. Novel report on six Fusarium species associated with head blight and crown rot of wheat in Basra province, Iraq. Bulletin of the National Research Centre, 43(1), 139. https://doi.org/10.1186/ s42269-019-0173-z.

11. Mirhosseini H.A., Babaeizad V. and Hashemi L. 2014. First report of Fusarium brachygibbosum causing leaf spot on oleander in Iran. Journal of Plant Pathology, 96, 431-439. http://dx.doi.org/10.4454/ JPP.V96I2.002.

12. Murray M.G. and Thompson W.F. 1980. Rapid isolation of high molecular weight plant DNA. Nucleic 
Acids Res. 8, 4321-4325.

13. Nei M. and Kumar S. 2000. Molecular Evolution and Phylogenetics. Oxford University Press, New York.

14. Rentería-Martínez M.E., Meza-Moller A., GuerraCamacho M.A., Romo-Tamayo F., Ochoa-Meza A. and Moreno-Salazar S.F. 2015. First report of watermelon wilting caused by Fusarium brachygibbosum in Sonora, Mexico. Plant Disease, 99(5), 729-729.

15. Rentería-Martínez M.E., Guerra-Camacho M.A., Ochoa-Meza A., Francisco Moreno-Salazar S., del Carmen Meza-Moller A. and Manuel GuzmánOrtíz J. 2019. Description and comparison among morphotypes of Fusarium brachygibbosum, $F$. falciforme and $F$. oxysporum pathogenic to watermelon in Sonora, México. Revista Mexicana de Fitopatología, 37(1).

16. Padwick G.W. 1945. Notes on Indian fungi III. Mycological Papers, 12, 1-15.

17. Punja Z.K., Scott C. and Chen S. 2018. Root and crown rot pathogens causing wilt symptoms on fieldgrown marijuana (Cannabis sativa L.) plants. Canadian journal of plant pathology, 40(4), 528-541.

18. Seidle A.J. 2016. Etiology, epidemiology, and management of Fusarium spp. causing cryptic cankers in cold-stored, bare-root propagated almond trees in California.

19. Shan L.Y., Cui W.Y., Zhang D.D., Zhang J., Ma N.N., Bao Y.M., Dai X.F. and Guo W. 2017. First report of Fusarium brachygibbosum causing maize stalk rot in China. Plant Disease 101(5), 837. https:// doi.org/10.1094/PDIS-10-16- 1465-PDN.

20. Stack A.J., Yaghmour M.A., Kirkpatrick S.C., Gordon T.R. and Bostock R.M. 2017. First report of Fusarium brachygibbosum causing cankers in cold stored, bare-root propagated almond trees in California. Plant Disease 101(2), 390-390. https://doi. org/10.1094/PDIS-06-16-0929-PDN.

21. Tan D.C., Flematti G.R., Ghisalberti E.L., Sivasithamparam K., Chakraborty S., Obanor F. and Barbetti M.J. 2011. Mycotoxins produced by Fusarium species associated with annual legume pastures and 'sheep feed refusal disorders' in Western Australia. Mycotoxin research, 27(2), 123-135. doi: 10.1007/ s12550-010-0085-0.

22. Tamura K., Stecher G., Peterson D., Filipski A., and Kumar S. 2013. MEGA6: Molecular Evolutionary Genetics Analysis version 6.0. Molecular Biology and Evolution, 30, 2725-2729.

23. Trabelsi R., Sellami H., Gharbi Y., Krid S., Cheffi M., Kammoun S., Dammak M., Mseddi A., Gdoura R. and Ali T.M. 2017. Morphological and molecular characterization of Fusarium spp. associated with olive trees dieback in Tunisia. Biotech 7, 28. https:// doi.org/10.1007/s13205-016-0587-3.

24. Van Coller G.J. 2013. Screening of South African wheat cultivars for resistance to Fusarium Head Blight (FHB). Report on the production year report to winter cereal trust.

25. White T.J., Bruns T., Lee S., Taylor J.W. 1990. Amplification and direct sequencing of fungal ribosomal RNA genes for phylogenetics. In: PCR Protocols: A Guide to Methods and Applications, eds. Innis M.A., Gelf D.H., Sninsky J.J. and White T.J. Academic Press, Inc. New York, pp. 315-322.

26. Xia B., Hu J.Y., Zhu X.F., Liang Y., Ren X., Wu Y.H. and Chen D.X. 2018. First report of sunflower broomrape wilt caused by Fusarium brachygibbosum in China. Plant disease, 102(11), 2372-2372. 